\title{
Badanie wytrzymałości na zrywanie wybranych magnesów o różnej sile przyciągania
}

\author{
A study on the strength of magnetic connections in magnets \\ with different retentive forces \\ ${ }^{1}$ Katedra i Zakład Protetyki Stomatologicznej, Uniwersytet Medyczny im. Piastów Śląskich we Wrocławiu \\ ${ }^{2}$ Laboratorium Napędów Hydraulicznych, Diagnostyki i Wibroakustyki, Wydział Mechaniczny \\ Politechnika Wrocławska
}

DOI: http://dx.doi.org/10.20883/df.2017.19

\begin{abstract}
Streszczenie
Wprowadzenie. Wykonanie uzupełnień protetycznych z użyciem magnetycznych elementów retencyjnych może być dobrym rozwiązaniem w leczeniu pacjentów posiadających uzębienie resztkowe. Ważnym zastosowaniem magnesów ziem rzadkich jest poprawa retencji protez poprzez dobór magnesu o odpowiedniej sile przyciągania.

Cel. Celem pracy było oszacowanie na podstawie badań na zrywanie faktycznej siły przyciągania magnesów.

Materiał i metody. Wykorzystując maszynę wytrzymałościową, zbadano siły zrywające magnesów japońskiej firmy Aichi: Magfit DX400, Magfit DX600, Magfit DX800 oraz Magfit DX1000. Magnes i keeper zostały umieszczone w bazie wykonanej z materiału akrylowego. Tak przygotowane próbki umieszczono w szczękach maszyny wytrzymałościowej. Prędkość zrywania wynosiła $50 \mathrm{~mm} / \mathrm{min}$ i obrazuje ona szacunkową szybkość, z jaką magnesy zamontowane w protezie tracą kontakt z podłożem w jamie ustnej pacjenta. Wyniki badań zostały poddane szeregowi testów statystycznych.

Wnioski. Wszystkie otrzymane do badań próbki wykazały statystyczną zgodność ze specyfikacją producenta oraz zgodność wzajemną. Z uwagi na szereg zalet, jakie posiadają magnetyczne elementy retencyjne, wykorzystywanie ich w codziennej praktyce protetycznej wydaje się słuszne.
\end{abstract}

Słowa kluczowe: protezy overdenture, magnesy, siły przyciągania.

\begin{abstract}
Introduction. Statement of proposition: magnetic retention may be a good method of attaching overdentures. It is therefore necessary to select the retentive capabilities of magnetic systems to ensure their effective performance.

Aim. The purpose of this study was to evaluate the actual attractive force of different magnetic attachments.

Material and Methods. The magnetic attachments used in this study were the Magfit DX400, Magfit DX600, Magfit DX800 and Magfir DX1000 (Aichi, Japan). Magnets and keepers were embedded in the centre of acrylic resin blocks which, according to the manufacturer, have no effect on the force delivered by the magnet. The attractive forces were measured using a universal testing machine at a crosshead speed of $50 \mathrm{~mm} / \mathrm{min}$. This separation approximated the speed of movement of the mandible away from the denture and its magnets during functional movements.

Conclusions. All the components obtained for examination showed a statistical conformity to specification and mutual compatibility. Rare earth magnets can be satisfactorily used in prosthodontics due to of their many advantages.
\end{abstract}

Keywords: overdentures, magnets, attractive force.

Magnetyczne systemy retencyjne używane w protetyce stomatologicznej złożone są z dwóch komponentów. Keepera, czyli metalowego krążka wykonanego ze stopu ferromagnetycznego (najczęściej kobaltowo-palladowego), który umieszczany jest w odpowiednio wypreparowanym korzeniu zęba lub wkręcany do wszczepu śródkostnego. Magnes, który umieszcza się w siodle protezy, to stop samaru, czyli metalu należącego do pierwiastków ziem rzadkich - lantanowców, z domieszką kobaltu, lub stop neodymu, boru i żelaza, szczelnie zamknięty w kapsule chroniącej przed korozją [1, 2].
Najczęstsze zastosowanie magnesów to poprawa retencji protez typu overdenture, szczególnie u pacjentów z chorym przyzębiem, gdyż nie przenoszą one sił bocznych na filary, a gdy siły przemieszczające protezę przekroczą siły przyciągania, nastąpi utrata kontaktu z zębem filarowym lub poprawa retencji protez pooperacyjnych. Niewątpliwą zaletą zaczepów magnetycznych jest ich niewielki rozmiar, umożliwiający zastosowanie w przypadku małej odległości międzywyrostkowej, oraz płaska powierzchnia, ułatwiająca utrzymanie dobrej higieny - szczególnie u pacjentów w pode- 
szłym wieku. Systemy magnetyczne cechuje łatwa naprawialność oraz nieskomplikowana procedura wykonania kliniczno-laboratoryjnego protez overdenture $z$ ich wykorzystaniem [3-5]. Po zacementowaniu keeperów $w$ jamie ustnej i wykonaniu protezy overdenture w sposób konwencjonalny pozycjonuje się magnesy. Należy je umieścić centralnie na keeperach, ponieważ gdy nastąpi ich przesunięcie, spada ich siła przyciągania. Aby uniknąć błędu przy pozycjonowaniu magnesów przez technika na modelu gipsowym, najlepiej zrobić to bezpośrednio w jamie ustnej pacjenta. Magnesy umieszcza się na keeperach, a bezpośrednio nad keeperami w protezie umieszczonej na podłożu wykonuje się otwory, przez które wykonuje się mikrowyciski. W tej formie magnesy w wycisku przekazywane są do laboratorium, gdzie następuje montaż magnesów w płycie protezy [6].

Siła połączenia keepera $z$ magnesem jest stała i w przeciwieństwie do innych elementów retencyjnych nie wymaga regulowania.

Celem pracy była ocena wytrzymałości na zrywanie magnesów o różnej sile, co pozwoliło na zbadanie ich faktycznej siły przyciągania.

Do badania wykorzystano magnesy japońskiej firmy Aichi: Magfit DX400, Magfit DX600, Magfit DX800 oraz Magfit DX1000 (stopy Nd-Fe-B), po trzy z każdego rodzaju, czyli razem wykonano 12 próbek. Maszyna, której użyto do badań, to standardowa maszyna wytrzymałościowa.

Przed przystąpieniem do pomiaru siły zrywającej połączenia magnetyczne próbki zostały tak przygotowane, aby zniwelować możliwe wpływy czynników zewnętrznych oraz zmaksymalizować dokładność wykonywanego badania. Bazy, do których zamocowano krążki magnetyczne, wykonano $\mathrm{z}$ materiału akrylowego, standardowo używanego jako materiał protetyczny. Na jednym z końców każdego z akrylowych trzpieni wykonano nagwintowany otwór. Pozwalał on na stabilne połączenie $z$ mosiężną śrubą, natomiast śruba wraz z nakrętkami służyła jako stabilny i nieodkształcalny uchwyt do zamocowania w szczękach maszyny wytrzymałościowej. Przeciwległy koniec każdej akrylowej bazy (na którym miał zostać umieszczony magnetyczny krążek) został zwężony, aby umożliwić kontrolę przylegania powierzchni magnesów podczas przeprowadzania badań. Wykonano to wykorzystując możliwości, jakie daje proces toczenia. Wspomniana śruba z nakrętkami również w tym przypadku posłużyła jako uchwyt w szczękach tokarki. Zapewniło to osiowość uchwytu z próbką oraz prostopadłość powierzchni akrylowej przeznaczonej pod krążki do osi całej próbki. Długość akrylowego trzpienia oraz mosiężne elementy mocowania umożliwiły izolację magnetyczną od szczęk maszyny wytrzymałościowej (Rycina 1).

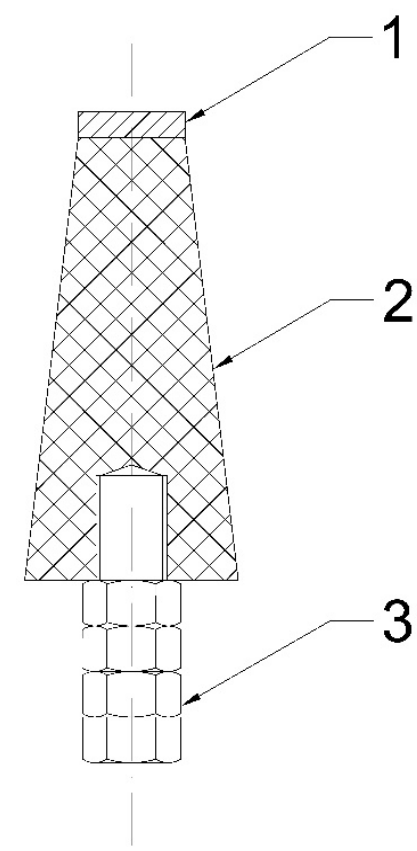

Rycina 1. Schemat pojedynczego trzpienia pomiarowego: 1. krążek magnesu, 2. akrylowa baza, 3. mosiężna śruba z nakrętkami

Figure 1. Measuring probe: 1. magnet disc, 2. acrylic base, 3. brass bolt with nuts

Otrzymane do badań zestawy magnesów protetycznych zostały losowo wybrane spośród asortymentu producenta. Rozerwanie połączenia magnetycznego dla każdej pary przeprowadzono dwunastokrotnie, za każdym razem zmieniając w losowy sposób względne kątowe położenie krążków. W ten sposób zasymulowane zostało wzajemne, losowe pozycjonowanie magnesów w jamie ustnej pacjentów. Prędkość zrywania par magnesów (keeper + magnes) na maszynie wytrzymałościowej wynosiła $50 \mathrm{~mm} / \mathrm{min}$. Prędkość ta obrazuje szacunkową szybkość, z jaką proteza traci kontakt $z$ podłożem protetycznym $w$ jamie ustnej pacjenta $[1,7]$. Uzyskane $w$ ten sposób wyniki przedstawiono w tabeli 1.

Podstawowe statystyki wyliczone na podstawie uzyskanych pomiarów przedstawiono w tabeli 2. Wartości średnie sił zrywania wykazują pewien stopień rozrzutu oraz rozbieżność względem wartości zadeklarowanych $\mathrm{w}$ specyfikacji. Producent nie wspomina nic o możliwym odchyleniu realnych wartości od normatywnej, więc nie ma z czym porównać uzyskanych odchyleń standardowych. Można jednak posłużyć się współczynnikiem zmienności. Współczynnik zmienności jest ilorazem odchylenia standardowego i wartości średniej. Ze względu na to, że podczas dzielenia 
Tabela 1. Wartości siły uzyskane dla poszczególnych par magnesów

Table 1. Force values for particular magnet pairs

\begin{tabular}{|c|c|c|c|c|c|c|c|c|c|c|c|c|c|}
\hline & & \multicolumn{3}{|c|}{ DX 400} & \multicolumn{3}{|c|}{ DX 600} & \multicolumn{3}{|c|}{ DX 800} & \multicolumn{3}{|c|}{ DX 1000} \\
\hline $\begin{array}{l}\text { Siła nominalna } \\
\text { (wg specyfikacji) }\end{array}$ & {$[\mathrm{N}]$} & \multicolumn{3}{|c|}{3,9} & \multicolumn{3}{|c|}{6,1} & \multicolumn{3}{|c|}{7,7} & \multicolumn{3}{|c|}{9,8} \\
\hline \multirow{12}{*}{$\begin{array}{l}\text { Zmierzona siła } \\
\text { rozerwania } \\
\text { połączenia }\end{array}$} & \multirow{12}{*}[\mathrm{N}]{} & 3,74 & 3,58 & 3,89 & 6,08 & 5,94 & 6,29 & 7,68 & 7,71 & 7,45 & 9,90 & 9,96 & 9,54 \\
\hline & & 4,26 & 4,06 & 3,96 & 6,21 & 6,23 & 6,07 & 7,50 & 7,95 & 7,59 & 9,69 & 9,74 & 9,87 \\
\hline & & 3,99 & 3,94 & 4,00 & 5,99 & 6,03 & 6,23 & 7,46 & 7,93 & 7,53 & 9,47 & 9,70 & 9,84 \\
\hline & & 3,89 & 3,82 & 4,00 & 6,10 & 6,26 & 6,14 & 7,65 & 8,02 & 7,61 & 10,04 & 9,66 & 9,94 \\
\hline & & 3,99 & 4,05 & 3,82 & 6,16 & 5,91 & 5,76 & 7,69 & 7,65 & 7,89 & 10,00 & 9,75 & 9,90 \\
\hline & & 3,88 & 3,71 & 3,91 & 6,21 & 5,78 & 5,88 & 7,78 & 7,51 & 7,68 & 10,06 & 9,71 & 10,15 \\
\hline & & 3,89 & 3,89 & 3,79 & 6,25 & 5,77 & 5,80 & 7,77 & 7,85 & 7,07 & 9,90 & 9,73 & 9,94 \\
\hline & & 4,08 & 3,87 & 3,80 & 6,11 & 6,17 & 6,01 & 7,73 & 7,53 & 7,62 & 9,96 & 9,73 & 9,76 \\
\hline & & 4,07 & 3,94 & 3,90 & 5,95 & 6,03 & 6,02 & 7,79 & 7,83 & 7,90 & 9,98 & 9,82 & 9,91 \\
\hline & & 4,07 & 3,93 & 4,04 & 6,03 & 6,03 & 5,92 & 7,33 & 7,12 & 7,67 & 9,79 & 9,73 & 9,87 \\
\hline & & 3,98 & 3,80 & 3,83 & 5,99 & 6,37 & 6,02 & 7,52 & 6,96 & 7,69 & 9,82 & 9,72 & 9,53 \\
\hline & & 3,76 & 3,90 & 3,93 & 6,34 & 6,13 & 5,89 & 7,74 & 7,61 & 7,39 & 9,97 & 9,86 & 9,80 \\
\hline
\end{tabular}

jednostki ulegają skróceniu, jest on bezwymiarowy. Zazwyczaj podaje się go w postaci procentowej i uznaje, że jeśli przekracza $10 \%$, to zmienna losowa charakteryzuje się statystycznie istotnym rozrzutem. Jednakże w przypadku badanych magnesów współczynnik ten nie przekracza nawet $5 \%$, można więc stwierdzić, że rozrzut uzyskanych wyników jest bardzo niewielki.

$\mathrm{Na}$ uzyskanych wynikach został przeprowadzony szereg testów statystycznych. Miały one na celu oszacowanie zależności zarówno między magnesami wewnątrz grup, jak i pomiędzy nimi. Pierwszym krokiem było przeprowadzenie testu parametrycznego, który wykazał, czy średnie wartości sił poszczególnych par magnesów są statystycznie różne od tych, które deklaruje producent. Ponieważ uzyskane próby są mało liczne $(n<30)$, należało do tego celu użyć testu na bazie rozkładu t-Studenta. Test ten wymaga, aby cecha w badanej populacji miała charakter rozkładu normalnego. Ponieważ rozkład normalny bardzo często modeluje procesy produkcyjne, $z$ dużym prawdopodobieństwem można to założenie w przypadku badanych magnesów protetycznych uznać za prawdziwe.

Do wszystkich wykonanych i przedstawionych w niniejszym artykule testów przyjęto poziom istotności $\alpha=0,05$. Poziom istotności testu określa poziom przyzwolenia na popełnienie błędu l-go rodzaju, czyli na odrzucenie hipotezy zerowej (jakakolwiek ona będzie w różnego rodzaju testach), podczas gdy w rzeczywistości będzie ona prawdziwa. Ogólnie zalecany poziom istotności równy 0,05 [8] wydaje się wystarczający, ponieważ badane zagadnienie nie dotyczy spraw szczególnej wagi, takich jak zdrowie i bezpieczeństwo pacjentów. Dopełnieniem poziomu istotności jest moc testu 1- $\beta$, która informuje o prawdopodobieństwie, z jakim można przyjąć testowaną hipotezę zerową za prawdziwą.

Z uwagi na charakter badania (czy magnesy posiadają zadeklarowaną wartość siły czy nie), na hipotezę alternatywną wybrano hipotezę dwustronną:

$$
\begin{aligned}
& \mathrm{H}_{0}: \mu=\mu_{0} \\
& \mathrm{H}_{1}: \mu \neq \mu_{0}
\end{aligned}
$$

gdzie:

$\mu$ - nieznana wartość średnia siły dla danej pary magnesów,

$\mu_{0}$ - wartość siły wg specyfikacji.

Dla obranej hipotezy dwustronnej obszar krytyczny jest następujący:

$$
P\left\{|t|>t_{\alpha}\right\}=\alpha
$$

gdzie:

t - statystyka t-Studenta,

$\mathrm{t}_{\alpha}$ - wartość krytyczna,

$\alpha$ - poziom istotności.

Tabela 3 w syntetycznej formie przedstawia wyliczenia testu t-Studenta dla posiadanych wyników. W rezultacie przeprowadzonego testu żadna z próbek magnesów nie spowodowała odrzucenia hipotezy o zgodności średniej wartości siły ze specyfikacją. Te przypadki próbek, dla których prawdopodobieństwo $p$ jest niewiele większe od poziomu istotności $\alpha$ (np. $p=0,06$ w tabeli 3), charakteryzują się jednak dość sporą mocą testu $(1-\beta=0,58$ w tabeli 3), co potwierdza przyjęcie hipotezy zerowej na statystycznie istotnym poziomie.

Wątpliwość budzi pierwsza próbka z grupy DX 800, dla której poziom istotności wynosi 0,17, 
Tabela 2. Zestawienie podstawowych statystyk dla własności wytrzymałościowych badanych par magnesów protetycznych (baza + magnes)

Table 2. Basic statistics for strength of studied prosthetic magnet pairs (keeper + magnet)

\begin{tabular}{|c|c|c|c|c|c|c|c|c|c|c|c|c|c|}
\hline & & \multicolumn{3}{|c|}{ DX 400} & \multicolumn{3}{|c|}{ DX 600} & \multicolumn{3}{|c|}{ DX 800} & \multicolumn{3}{|c|}{ DX 1000} \\
\hline Siła nominalna & {$[\mathrm{N}]$} & \multicolumn{3}{|c|}{3,9} & \multicolumn{3}{|c|}{6,1} & \multicolumn{3}{|c|}{7,7} & \multicolumn{3}{|c|}{9,8} \\
\hline Wartość średnia & {$[\mathrm{N}]$} & 3,98 & 3,88 & 3,91 & 6,12 & 6,05 & 6,00 & 7,64 & 7,64 & 7,59 & 9,88 & 9,76 & 9,84 \\
\hline Odchylenie standardowe & {$[\mathrm{N}]$} & 0,15 & 0,13 & 0,08 & 0,12 & 0,19 & 0,16 & 0,15 & 0,33 & 0,22 & 0,17 & 0,08 & 0,17 \\
\hline Współczynnik zmienności & {$[-]$} & $3,7 \%$ & $3,5 \%$ & $2,1 \%$ & $1,9 \%$ & $3,1 \%$ & $2,7 \%$ & $2,0 \%$ & $4,3 \%$ & $2,9 \%$ & $1,7 \%$ & $0,9 \%$ & $1,7 \%$ \\
\hline
\end{tabular}

Tabela 3. Wyniki dwustronnego testu t-Studenta, wpływające na równość z nominalną wartością siły $(p r z y ~ \alpha=0,05)$ Table 3. Results of bilateral $t$-Student test affecting equality with nominal strength value

\begin{tabular}{|l|c|c|c|c|c|c|c|c|c|c|c|c|}
\hline & \multicolumn{3}{|c|}{ DX 400 } & \multicolumn{3}{c|}{ DX 600 } & \multicolumn{3}{c|}{ DX 800 } & \multicolumn{3}{c|}{ DX 1000 } \\
\hline Siła nominalna $\mu_{0}$ & {$[\mathrm{~N}]$} & \multicolumn{3}{|c|}{3,9} & \multicolumn{3}{c|}{6,1} & \multicolumn{3}{c|}{9,8} \\
\hline Statystyka $t$ & 1,98 & $-0,56$ & 0,21 & 0,53 & $-0,86$ & $-2,13$ & $-1,50$ & $-0,64$ & $-1,71$ & 1,65 & $-1,73$ & 0,77 \\
\hline Wartość krytyczna $t_{\alpha}$ & \multicolumn{7}{|c|}{$2,20(\alpha=0,05)$} & & & & \\
\hline Odrzucenie $h_{0}$ & & & & & & & & & & & & \\
\hline Prawdopodobieństwo testowe $p$ & 0,14 & 0,52 & 0,81 & 0,60 & 0,41 & 0,06 & 0,17 & 0,53 & 0,12 & 0,12 & 0,11 & 0,46 \\
\hline Moc testu 1- $\beta$ & 0,46 & 0,08 & 0,07 & 0,09 & 0,15 & 0,58 & 0,28 & 0,10 & 0,41 & 0,37 & 0,41 & 0,13 \\
\hline
\end{tabular}

a moc testu 0,28. Obie wartości są dość niskie, co oznacza, że mimo nieodrzucenia hipotezy o równości średniej próbki z siłą 7,7 N nie należy jej przyjmować, bowiem prawdopodobieństwo jej słuszności jest niewielkie (28\%).

Ponieważ zestawy magnesów, które otrzymano, zostały dobrane w sposób losowy, uznano, że warto sprawdzić, czy wartości z nich uzyskane mają podobne do siebie rozkłady prawdopodobieństwa. Zdarza się bowiem, że produkty pochodzące $z$ różnych serii produkcyjnych, takie same co do średnich wartości swoich parametrów, różnią się jednak ich rozrzutem. Może to być przyczyną braku możliwości utrzymania powtarzalności efektu końcowego (w naszym przypadku - sił stabilizujących protezy). Zatem aby stwierdzić, czy uzyskane próby mają jednakowe rozkłady sił, należało przeprowadzić jednoczynnikową analizę wariancji ANOVA (ang. analysis of variance).

Analiza ta ma jednak szereg założeń, które muszą spełniać badane próby statystyczne:

- posiadane próby statystyczne muszą być pozyskane w sposób niezależny,

- posiadane próby statystyczne muszą być losowymi próbami prostymi,

- każda populacja, z której pochodzą próby statystyczne, musi mieć rozkład normalny,

- populacje, z których pochodzą próby statystyczne muszą mieć jednakowe wariancje.

Warunki a. i b. zostały spełnione podczas badania par magnesów. Co do warunków c. i d. nie ma żadnych pewnych informacji, więc należało przeprowadzić testy, aby to sprawdzić. Wobec tego przed przystąpieniem do analizy ANOVA należało przeprowadzić test Shapiro-Wilka na zgodność z rozkładem normalnym oraz test Bartlett'a na jednorodność wariancji.

Test Shapiro-Wilka jest nieparametrycznym testem do sprawdzania normalności rozkładu zmiennej losowej. W swojej grupie testów jest uznawany za najlepszy ze względu na największą moc, czyli na prawdopodobieństwo niepopełnienia błędu przy przyjmowaniu hipotezy zerowej za prawdziwą. Jedyne ograniczenie tego testu dotyczy liczebności próby statystycznej, która nie może przekraczać 5000. Przedstawione badanie zdecydowanie jednak nie przekracza tej wartości. Hipotezy składające się na test Shapiro-Wilka mają postać:

$\mathrm{H}_{0}$ :próba statystyczna pochodzi z populacji o rozkładzie normalnym

$\mathrm{H}_{1}$ : próba statystyczna nie pochodzi z populacji o rozkładzie normalnym.

Obszar krytyczny tego testu jest lewostronny, co oznacza, że cały test zasadza się na nierówności:

$$
P\left\{W<W_{\alpha}\right\}=\alpha,
$$

gdzie:

W - statystyka testowa obliczona na podstawie próby statystycznej,

$W_{\alpha}$ - wartość krytyczna odczytana z tablic Sha-

piro-Wilka dla poziomu istotności $\alpha$ i liczności próby $n$.

Wyniki uzyskane z powyższego testu (Tabela 4) porównano zgodnie z zależnością (2) wskazują, iż w żadnym z badanych przypadków hipotezy o normalności rozkładu populacji nie da się odrzucić. Ewentualną wątpliwość może jedynie 
Tabela 4. Wyniki testu Shapiro-Wilka dla każdego zestawu magnesów (przy $\alpha=0,05$ )

Table 4. Results of Shapiro-Wilk test for each magnet set

\begin{tabular}{|c|c|c|c|c|c|c|c|c|c|c|c|c|c|}
\hline & & \multicolumn{3}{|c|}{ DX 400} & \multicolumn{3}{|c|}{ DX 600} & \multicolumn{3}{|c|}{ DX 800} & \multicolumn{3}{|c|}{ DX 1000} \\
\hline Siła nominalna & {$[\mathrm{N}]$} & \multicolumn{3}{|c|}{3,9} & \multicolumn{3}{|c|}{6,1} & \multicolumn{3}{|c|}{7,7} & \multicolumn{3}{|c|}{9,8} \\
\hline \multicolumn{2}{|c|}{ Statystyka testowa $W$} & 0,96 & 0,93 & 0,94 & 0,96 & 0,97 & 0,97 & 0,88 & 0,90 & 0,91 & 0,86 & 0,92 & 0,89 \\
\hline Wartość krytycz & & \multicolumn{12}{|c|}{$0,86(\alpha=0,05)$} \\
\hline \multicolumn{2}{|l|}{ Odrzucenie $\mathrm{H}_{0}$} & & & & & & & & & & & & \\
\hline \multicolumn{2}{|c|}{ Prawdopodobieństwo testowe $p$} & 0,72 & 0,36 & 0,56 & 0.85 & 0,87 & 0,88 & 0.10 & 0,16 & 0,17 & 0,05 & 0,32 & 0,11 \\
\hline
\end{tabular}

budzić dość niska w niektórych przypadkach wartość prawdopodobieństwa $p$. W szczególności dotyczy to grupy DX 800, dla której wartości $p$ są zbliżone i wszystkie są dość niskie.

Do sprawdzenia jednorodności wariancji zastosować można test Bartlett'a lub test Levene'a. Pierwszy z nich ma jednak większą moc, jeśli spełniony jest warunek o normalności rozkładu. Ponieważ wszystkie próbki pomyślnie przeszły test Shapiro-Wilka, korzystniejsze będzie skorzystanie z testu Bartlett'a.

Wariancje powinny być jednakowe wewnątrz każdej grupy próbek. Zatem hipotezy tego testu skonstruowane są następująco:

$$
\mathrm{H}_{0}: \sigma_{1}^{2}=\sigma_{2}^{2}=\sigma_{3}^{2}
$$

$\mathrm{H}_{1}$ : nie wszystkie $\sigma^{2}$ są równe

gdzie $\sigma_{1}^{2}, \sigma_{2}^{2}, \sigma_{3}^{2}$ to wariancje dla próbek par magnesów w obrębie jednej grupy.

Test ten opiera się na wartościach krytycznych pochodzących $z$ rozkładu $\chi^{2}$ i jest prawostronny, a zatem należy sprawdzić, czy badane próbki spełniają zależność:

$$
P\left\{\chi^{2}>\chi_{\alpha}^{2}\right\}=\alpha,
$$

gdzie:

$\chi^{2}$ - statystyka testowa obliczona na podstawie próby statystycznej,

$\chi_{\alpha}^{2}$ - wartość krytyczna wynikająca z rozkładu $\chi^{2}$ dla poziomu istotności $\alpha$ i stopni swobody próby $\mathrm{n}-1$.

Jak wynika z tabeli 5 i zależności (3), w grupie DX 800 należało odrzucić hipotezę zerową o jednorodności wariancji znajdujących się w nich próbek. Na podstawie posiadanych danych należy więc stwierdzić, że rozrzut wartości sił w próbkach tej grupy jest istotnie zróżnicowany. Oznacza to, że wartości sił w zależności od wzajemnego położenia keepera i magnesu są w przypadku jednej pary bardziej, a w przypadku innej mniej rozrzucone względem wartości średniej.
Po stwierdzeniu normalności rozkładów populacji i jednorodności wariancji można przystąpić do badania podobieństwa rozkładów sił próbek w obrębie każdej grupy magnesów. Ponieważ jednak grupa DX 800 nie przeszła testu na jednorodność wariancji, w jej przypadku nie można było skorzystać z analizy ANOVA. Wykorzystano więc test Kruskala-Wallisa. Jest to test o mniejszej mocy niż ANOVA, ale jednocześnie nie jest obwarowany żadnymi wymaganiami co do wariancji czy kształtu rozkładów w populacjach.

Dla grup magnesów DX 400, DX 600 i DX 1000 przeprowadzenie analizy ANOVA rozpoczyna się od ustanowienia hipotez:

$$
\mathrm{H}_{0}: \mu_{1}=\mu_{2}=\mu_{3}
$$

$\mathrm{H}_{1}$ : nie wszystkie $\mu$ są równe

gdzie:

$\mu_{1}, \mu_{2}, \mu_{3}$ - wartości średnie dla próbek par magnesów w obrębie jednej grupy.

Jak można zauważyć, test ten jest skonstruowany w taki sposób, że statystyczne podobieństwo rozkładów cech bada się poprzez stwierdzanie równości wartości średnich w poszczególnych populacjach. Nie ma tu też szczególnego znaczenia liczba prób, może ich być dowolnie dużo. Jednakże odpowiedź, jaką daje ten test, dotyczy równości wszystkich średnich jednocześnie. Jeśli choćby jedna z nich byłaby inna niż pozostałe, hipoteza zerowa zostanie odrzucona, ale bez wskazania z powodu której wartości.

Testowanie $w$ analizie ANOVA oparte jest na rozkładzie F-Snedecora i jest to test prawostronny, zatem obliczoną z prób statystykę $F$ porównuje się z obszarem krytycznym według wzoru:

$$
P\left\{F>F_{\alpha}\right\}=\alpha,
$$

gdzie:

F - statystyka testowa obliczona na podstawie prób statystycznych,

$F_{\alpha}$ - wartość krytyczna odczytana z rozkładu F-Snedecora dla poziomu istotności $\alpha$ i ogólnej liczby stopni swobody. 
Tabela 5. Wyniki testu Bartlett'a na homogeniczność wariancji (przy $\alpha=0,05$ )

Table 5. Results of Bartlett test measurement variance homogeneity

\begin{tabular}{|l|c|c|c|c|c|}
\hline \multicolumn{2}{|l|}{} & DX 400 & DX 600 & DX 800 & DX 1000 \\
\hline Siła nominalna & {$[\mathrm{N}]$} & 3,9 & 6,1 & 7,7 & 9,8 \\
\hline Statystyka testowa $\chi^{2}$ & 3,33 & 2,10 & 6,18 & 4,28 \\
\hline Wartość krytyczna $\chi_{a}^{2}$ & \multicolumn{5}{|c|}{$5,99(\alpha=0,05)$} \\
\hline Odrzucenie $\mathrm{H}_{0}$ & & & & \\
\hline Prawdopodobieństwo testowe $p$ & 0,19 & 0,35 & 0,05 & 0,12 \\
\hline
\end{tabular}

Tabela 6. Wyniki jednokierunkowej analizy wariancji ANOVA

Table 6. Results of monodirectional ANOVA variance analysis

\begin{tabular}{|c|c|c|c|c|}
\hline & & DX 400 & DX 600 & DX 1000 \\
\hline Siła nominalna & {$[\mathrm{N}]$} & 3,9 & 6,1 & 9,8 \\
\hline \multicolumn{2}{|c|}{ Statystyka testowa $F$} & 1,71 & 1,60 & 1,29 \\
\hline \multicolumn{2}{|c|}{ Wartość krytyczna $F_{\alpha}$} & \multicolumn{3}{|c|}{$3,28(\alpha=0,05)$} \\
\hline \multicolumn{2}{|l|}{ Odrzucenie $\mathrm{H}_{0}$} & & & \\
\hline \multicolumn{2}{|c|}{ Prawdopodobieństwo testowe $p$} & 0,2 & 0,22 & 0,29 \\
\hline \multicolumn{2}{|l|}{ Moc testu $1-\beta$} & 0,42 & 0,33 & 0,43 \\
\hline
\end{tabular}

Tabela 7. Rezultaty testu Kruskala-Wallisa dla próbek w grupie DX 800

Table 7. Results of Kruskal-Wallis test for samles in group SX 800

\begin{tabular}{|c|c|c|}
\hline & & DX 800 \\
\hline Siła nominalna & {$[\mathrm{N}]$} & 7,7 \\
\hline \multicolumn{2}{|c|}{ Statystyka testowa $H$} & 1,00 \\
\hline \multicolumn{2}{|c|}{ Wartość krytyczna $\chi_{a}^{2}$} & $5,99(\alpha=0,05)$ \\
\hline \multicolumn{2}{|c|}{ Odrzucenie $\mathrm{H}_{0}$} & \\
\hline \multicolumn{2}{|c|}{ Prawdopodobieństwo testowe $p$} & 0,61 \\
\hline
\end{tabular}

W wyniku testu hipoteza zerowa o równości średnich w każdej $z$ badanych prób nie została odrzucona (Tabela 6). Wynika z tego, że w obrębie każdej grupy pary magnesów wykazują zbliżony do siebie rozkład sił. Prawdopodobieństwo $p$ kilkukrotnie (4-6 razy) przewyższa poziom istotności $\alpha$, czyli prawdopodobieństwo popełnienia błędu poprzez odrzucenie prawdziwej hipotezy zerowej jest od 4 do 6 razy większe. Obliczono również moc przeprowadzonych testów $(1-\beta)$ z której wynika, że hipotezę o równości rozkładów w każdej grupie można przyjąć z prawdopodobieństwem od $33 \%$ do $43 \%$.

Równość rozkładów dla prób w grupie DX 800, ze względu na nierówność wariancji stwierdzoną w teście Bartlett'a, należało sprawdzić stosując test Kruskala-Wallisa. Jest to nieparametryczny test rangowy umożliwiający porównywanie do siebie więcej niż dwóch prób. Ma bardzo łagodne warunki stosowania, gdyż nie wymaga normalności rozkładów zmiennych w badanych próbach, równości ich wariancji ani równoliczności. Jego konstrukcja zasadza się na porównywaniu dystrybuant, a zatem hipotezy są następujące:

$$
\begin{gathered}
\mathrm{H}_{0}: F_{1}=F_{2}=F_{3} \\
\mathrm{H}_{1}: \text { nie wszystkie F są równe }
\end{gathered}
$$

gdzie $F_{1}, F_{2}, F_{3}$ to dystrybuanty dla sił rozrywajacych próbki par magnesów w obrębie grupy DX 800 . Jest to test prawostronny, oparty na obszarze krytycznym rozkładu $\chi^{2}$, a zatem sprawdza się, czy wyliczone z prób wartości spełniają zależność:

$$
P\left\{H>\chi_{\alpha}^{2}\right\}=\alpha
$$

gdzie:

$H$ - statystyka testowa obliczona na podstawie próby statystycznej,

$\chi_{\alpha}^{2}$ - wartość krytyczna odczytana z rozkładu $\chi^{2}$ dla poziomu istotności $\alpha$ i stopni swobody próby $n-1$. 
Jak prezentuje tabela 7 , próbki w grupie DX 800 nie spełniają zależności (5), a zatem nie można odrzucić hipotezy o statystycznym podobieństwie ich rozkładów. Prawdopodobieństwo $p$ jest bardzo wysokie w stosunku do $\alpha$, co dodatkowo wzmacnia ten wniosek.

Zasadniczo wszystkie otrzymane do badań próbki magnesów wykazały statystyczną zgodność ze specyfikacją producenta oraz zgodność ze sobą wzajemnie. W praktyce oznacza to, że zarówno keepery, jak i magnesy zostały wyprodukowane w prawie powtarzalny sposób. Zmienność sił rozrywających wyrażona w odchyleniu standardowym i współczynniku zmienności jest dość niska, co zapewnia wystarczającą wartość tej siły niezależnie od wzajemnego położenia krążków.

Analiza wariancji i testy jej towarzyszące również wykazały powtarzalny charakter sił $\mathrm{w}$ badanych próbkach. Niewielkie odchylenie od tego wniosku wykazują próbki z grupy DX 800. Może to świadczyć o pochodzeniu tych próbek z różnych serii produkcyjnych. Na obecnym etapie trudno to jednak potwierdzić. Dokładniejsze badania w tym kierunku należałoby przeprowadzić, mając do dyspozycji większą liczbę próbek.

Zastosowanie magnesów ziem rzadkich u pacjentów z uzębieniem resztkowym jest dobrym rozwiązaniem. Ich mały rozmiar ułatwia wykonanie uzupełnień protetycznych nawet u pacjentów ze zmniejszoną odległością międzywyrostkową, a ich siły przyciągania (4-10 N) umożliwiają zachowanie odpowiedniej retencji.

\section{Wnioski}

1. Wszystkie otrzymane do badań próbki wykazały statystyczną zgodność ze specyfikacją producenta oraz zgodność wzajemną.

2. Z uwagi na szereg zalet, jakie posiadają magnetyczne elementy retencyjne, wydaje się słuszne wykorzystywanie ich w codziennej praktyce protetycznej.

\section{Oświadczenia}

Oświadczenie dotyczące konfliktu interesów

Autorzy deklarują brak konfliktu interesów w autorstwie oraz publikacji pracy.

\section{Źródła finansowania}

Autorzy deklarują brak źródeł finansowania.

\section{Piśmiennictwo}

[1] Funda A, Gülsen C. Retentive characteristics of different dental magnetic systems. J Prosthet Dent. 1995;10:422427.

[2] Riley MA, Walmsley AD, Harris IR. Magnets in prosthetic dentistry. J Prosthet Dent. 2001;86:37-142.

[3] Brusiłowicz N, Więckiewicz W. Magnetyczne elementy retencyjne stosowane $\mathrm{w}$ protetyce stomatologicznej. MS. 2015;12:26-29.

[4] Leem HW, Cho IH, Lee JH, Choi YS. A study on the changes in attractive force of magnetic attachments for overdenture. J Adv Prosthodont. 2016;8:9-15.

[5] Stendera P. Zastosowanie magnesów w protetyce stomatologicznej - czéść I: przegląd piśmiennictwa. Prot Stom. 1996;XLVI(3):160-164.

[6] Kittel M. Magnetyczne systemy retencyjne MPER w leczeniu protetycznym - bardzo skuteczna i ciekawa alternatywa tradycyjnych, precyzyjnych systemów retencyjnych. Stomatol Współcz. 2007;2:34-42.

[7] Akin H, Coskun ME, Akin EG, Ozdemir AK. Evaluation of the attractive force of different types of new - generation magnetic attachment systems. J Prosthet Dent. 2011;105 (3):203-207.

[8] Fisher, Ronald A, Statistical Methods for Research Workers. Edinburgh, UK: Oliver and Boyd, 1925.

Zaakceptowano do edycji: 2017-09-01

Zaakceptowano do publikacji: 2017-11-02

\author{
Adres do korespondencji: \\ Natalia Brusiłowicz \\ Katedra i Zakład Protetyki Stomatologicznej UM \\ ul. Krakowska 26, 50-425 Wrocław \\ tel.: 717840291 \\ e-mail: n.brusilowicz@gmail.com \\ Weronika Huss \\ Politechnika Wrocławska \\ Wybrzeże Wyspiańskiego, 50-370 Wrocław \\ e-mail:weronika.huss@pwr.edu.pl
}

